\title{
OPEN Effects of deep neuromuscular block with low-pressure pneumoperitoneum on respiratory mechanics and biotrauma in a steep Trendelenburg position
}

\author{
Ji Eun Kim ${ }^{1}$, Sang Kee Min ${ }^{1}$, Eunji Ha ${ }^{1}$, Dongchul Lee ${ }^{2}$, Jong Yeop Kim ${ }^{1,3 凶}$ \& \\ Hyun Jeong Kwak ${ }^{2,3 凶}$
}

We hypothesized that deep neuromuscular blockade (NMB) with low-pressure pneumoperitoneum (PP) would improve respiratory mechanics and reduce biotrauma compared to moderate NMB with high-pressure PP in a steep Trendelenburg position. Seventy-four women undergoing robotic gynecologic surgery were randomly assigned to two equal groups. Moderate NMB group was maintained with a train of four count of 1-2 and PP at $12 \mathrm{mmHg}$. Deep NMB group was maintained with a post-tetanic count of 1-2 and PP at $8 \mathrm{mmHg}$. Inflammatory cytokines were measured at baseline, at the end of PP, and $24 \mathrm{~h}$ after surgery. Interleukin- 6 increased significantly from baseline at the end of PP and $24 \mathrm{~h}$ after the surgery in moderate NMB group but not in deep NMB group

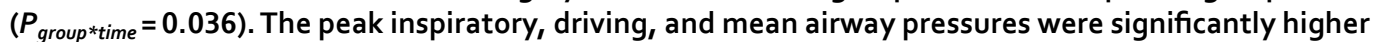
in moderate NMB group than in deep NMB group at $15 \mathrm{~min}$ and $60 \mathrm{~min}$ after PP $\left(P_{\text {group } * \text { time }}=0.002\right.$, 0.003 , and 0.048 , respectively). In conclusion, deep NMB with low-pressure PP significantly suppressed the increase in interleukin- 6 developed after $P P$, by significantly improving the respiratory mechanics compared to moderate NMB with high-pressure PP during robotic surgery.

Laparoscopic surgery has become very popular due to less surgical stress response and better clinical effects including reduced operation time, bleeding, opioid requirement, and hospital stay, when compared to open surgery $^{1,2}$. Recently, robotic surgery, which offers higher precision, faster recovery, and shorter hospitalization compared with laparoscopy, has gained popularity ${ }^{3}$. However, it requires prolonged pneumoperitoneum (PP) and steep Trendelenburg position, which can cause physiologic changes promoted by elevated intra-abdominal pressure (IAP), consequently giving rise to significant ischemia in abdominal organs and even in remote organs such as the lungs ${ }^{4,5}$. In addition, the cephalic elevation of the diaphragm markedly decreases the compliance of the respiratory system and tidal volume during the surgery.

International guidelines recommend the use of 'the lowest IAP allowing adequate exposure of the operative field rather than a routine pressure ${ }^{6}$, and deep neuromuscular blockade (NMB), which improves surgical space conditions and facilitates the lowering of IAP, thus enhancing the satisfaction of the surgeon ${ }^{7}$. Because of the ability of sugammadex to antagonize rocuronium rapidly at any level of NMB, it is possible to continue the deep NMB until the end of surgery. In a meta-analysis, overall quality of evidence for advantages of low-pressure PP compared to high-pressure PP was evaluated ${ }^{8}$; however, these results did not consider the depth of NMB at all.

Ventilator-induced lung injury is caused by repetitive stress and/or strain on the lungs, which releases the mediators associated with activation of the immune response, further adding to lung injury and systemically causing distal organ dysfunction; this is termed biotrauma'. Pulmonary biotrauma is lessened by prone position, recruitment maneuver, and extracorporeal techniques ${ }^{9,10}$. Protective lung ventilation with low tidal volume and low positive end-expiratory pressure (PEEP) during laparoscopy reduced pulmonary complications ${ }^{11}$ but seemed

\footnotetext{
${ }^{1}$ Department of Anesthesiology and Pain Medicine, Ajou University School of Medicine, 164, World cup-ro, Yeongtong-gu, Suwon, Republic of Korea. ${ }^{2}$ Department of Anesthesiology and Pain Medicine, Gil Medical Center, Gachon University College of Medicine, 774, Namdong-daero, Namdong-gu, Incheon, Republic of Korea. ${ }^{3}$ These authors contributed equally: Jong Yeop Kim and Hyun Jeong Kwak. ${ }^{\circledR}$ email: kjyeop@ajou.ac.kr; hyun615@ gilhospital.com
} 


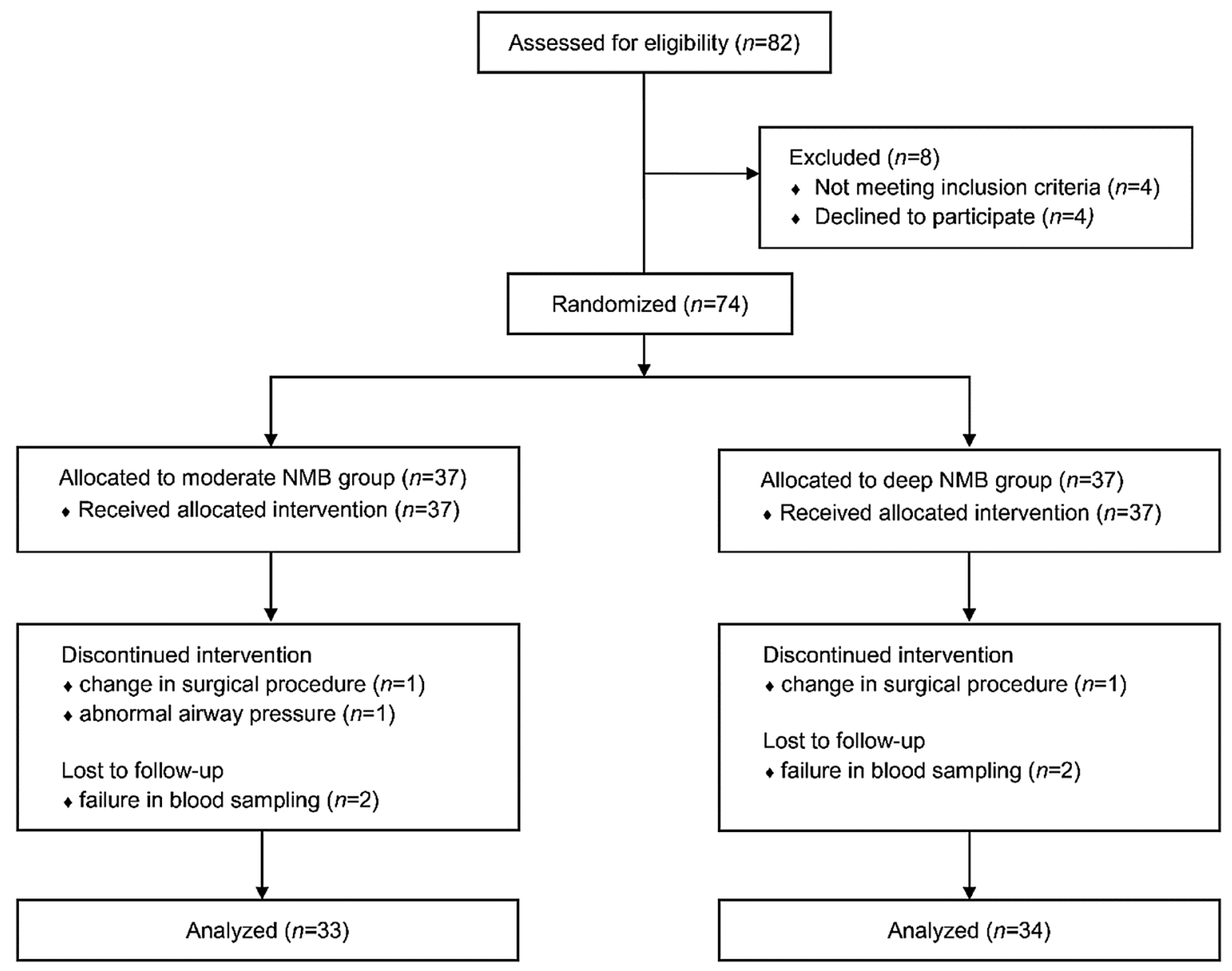

Figure 1. Patient allocation diagram. Abbreviations: $N M B$ neuromuscular block.

to be not enough to reduce the biotrauma ${ }^{12}$. In a meta-analysis, early administration of an NMB agent was found to improve the outcomes by decreasing biotrauma in cases of acute respiratory distress syndrome (ARDS) ${ }^{13}$. Meanwhile, there is still no clinical research on deep NMB combined with low-pressure PP that would improve the respiratory condition and reduce inflammation during mechanical ventilation. We hypothesized that deep NMB combined with low-pressure PP would improve respiratory mechanics and then reduce biotrauma compared to moderate NMB combined with high-pressure PP during protective lung ventilation.

The aim of this study was to evaluate the effects of deep NMB combined with low-pressure PP and moderate $\mathrm{NMB}$ combined with high-pressure PP on respiratory mechanics and biotrauma during protective lung ventilation for robotic gynecologic surgery in a steep Trendelenburg position.

\section{Results}

A total of 74 patients were enrolled and randomized, but 7 patients were excluded because of a change in the surgical procedure $(n=2)$, abnormal airway pressure $(n=1)$, and failure in blood sampling $(n=4)$ (Fig. 1$)$. There were no significant differences in patient characteristics and operation details (Table 1).

In post hoc analysis of cytokines, IL-6 level increased significantly from baseline at the end of PP and $24 \mathrm{~h}$ after the surgery in the moderate NMB group $(P=0.014$ and $P=0.001$, respectively), whereas there was no significant change in the deep NMB group (Fig. 2). TNFR-1 level increased significantly from baseline after PP in both groups $(P<0.001$ in all $)$ and was significantly higher in the moderate NMB group than the deep NMB group at the end of PP and $24 \mathrm{~h}$ after the surgery $(P=0.038$ and $P=0.046$, respectively, Fig. 2). IL-10 was not detected at baseline in the deep NMB group, but the levels were similar between the two groups at the end of PP and $24 \mathrm{~h}$ after the surgery. IL- 4 level at baseline was similar between the two groups, but IL- 4 at the other 2 time points and TNF- $\alpha$ at all time points were not detected in both groups (all zero, data not shown).

There was a significant interaction between group and time in Ppeak, Pplat, Pdriving, and Pmean (Table 2). In post hoc analysis, Ppeak was significantly higher in the moderate NMB group than in the deep NMB group at $15 \mathrm{~min}, 60 \mathrm{~min}$ after $\mathrm{PP}$, and at the end of surgery $(P=0.002, P<0.001$, and $P=0.035$, respectively). In addition, Pplat and Pdriving were significantly higher in the moderate NMB group than in the deep NMB group at 15 min and $60 \mathrm{~min}$ after $\mathrm{PP}(P=0.004$ and $P<0.001$, respectively). Moreover, Pmean was significantly higher in the moderate NMB group than in the deep NMB group at $15 \mathrm{~min}$ and $60 \mathrm{~min}$ after PP (both $P=0.005$ ). IAP was adequately maintained at approximately 8 or $12 \mathrm{mmHg}$, according to the group, throughout $\mathrm{PP}$ without changing the pressure level. 


\begin{tabular}{|c|c|c|}
\hline & Moderate NMB $(n=33)$ & Deep NMB $(n=34)$ \\
\hline Age (year) & $44(9)$ & $43(7)$ \\
\hline Weight (kg) & $57(9)$ & $58(11)$ \\
\hline Height $(\mathrm{cm})$ & $158(5)$ & $158(5)$ \\
\hline Body mass index $\left(\mathrm{kg} / \mathrm{m}^{2}\right)$ & $23(4)$ & $23(4)$ \\
\hline ASA physical status $(1 / 2)$ & $28 / 5$ & $28 / 6$ \\
\hline Type of operation & $10 / 18 / 5$ & $7 / 20 / 7$ \\
\hline \multicolumn{3}{|l|}{ (Hysterectomy/myomectomy/others ${ }^{\star}$ ) } \\
\hline \multicolumn{2}{|l|}{ Intraoperative } & \\
\hline Propofol (mg) & $1300[700-2200(1100-1500)]$ & $1000[400-3000(1000-1300)]$ \\
\hline Remifentanil $(\mu \mathrm{g})$ & $1906[1000-4000(1600-2000)]$ & $2000[400-3000(1400-2000)]$ \\
\hline Urine output $(\mathrm{mL})$ & $100[30-530(65-160)]$ & $90[35-400(60-125)]$ \\
\hline Bleeding loss (mL) & $100[10-500(30-100)]$ & $100[10-500(50-130)]$ \\
\hline Duration of operation (min) & $143(62)$ & $129(42)$ \\
\hline Duration of anesthesia (min) & $182(69)$ & $169(49)$ \\
\hline Duration of pneumoperitoneum (min) & $100[40-273(73-120)]$ & $90[40-192(75-120)]$ \\
\hline Duration of hospital stay (days) & $4[2-7(3-4)]$ & $3[2-5(3-4)]$ \\
\hline
\end{tabular}

Table 1. Patients characteristics and operative details. Values are presented as mean (standard deviation), median [range (interquartile range)], and the number of patients. Abbreviations: $N M B$ neuromuscular block, $A S A$ American Society of Anesthesiologists, $R B C$ red blood cell. *Includes staging, salpingo-oophorectomy, cystectomy, and uterovaginal prolapse.

White blood cell counts and CRP levels were similar between the two groups (Table 3). The number of patients with CRP $>0.5 \mathrm{mg} / \mathrm{dL}$ was similar in the moderate and deep NMB groups [26 (79\%) vs $30(88 \%), P=0.340$ ]. The intergroup differences in changes in $\mathrm{HR}, \mathrm{MAP}, \mathrm{pH}, \mathrm{PaCO}_{2}$, and $\mathrm{PaO}_{2} / \mathrm{FiO}_{2}$ ratio from baseline were comparable

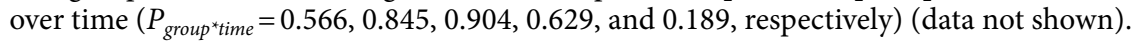

\section{Discussion}

This randomized controlled trial is the first study to evaluate the effect of deep NMB combined with low-pressure $\mathrm{PP}$ on respiratory mechanics and biotrauma during protective lung ventilation against $\mathrm{PP}$. We demonstrated that in patients undergoing robotic gynecologic surgery, deep NMB combined with low-pressure PP significantly suppressed the increase in IL-6 level developed after PP, by significantly improving the respiratory mechanics compared with moderate NMB combined with high-pressure PP.

Increased IAP itself causes inflammatory-induced lung damage after $\mathrm{PP}^{8,14}$, although laparoscopy has clear benefits in terms of reduced inflammatory response compared to open surgery ${ }^{6,15}$. Recently, it has been reported that IL 1- $\beta$, IL-6, and TNF- $\alpha$ levels increased in lung tissue as IAP increased, which was confirmed by histologic examination ${ }^{14}$. Among randomized controlled trials in humans, Schietroma et al. observed a significant decrease in IL-1, IL-6, and CRP levels ${ }^{16}$, and Basgual et al. observed a lower increase in IL-6 level up to 24 h postoperatively in low-pressure PP compared to high-pressure $\mathrm{PP}^{17}$. However, Perrakis et al. and Torres et al. did not show any difference regarding levels of CRP, IL-6, IL-8, IL-10, and white blood cell count in low-pressure PP ${ }^{18,19}$. Rather, Vijayaraghavan et al. found a higher increase in CRP level at $24 \mathrm{~h}$ postoperatively in low-pressure $\mathrm{PP}^{20}$. However, these studies were performed in reverse Trendelenburg position and did not consider the depth of NMB.

In this study, we investigated the changes in inflammatory markers in moderate and deep NMB states by adding the concept of high- or low-pressure PP in female patients in the Trendelenburg position. As a result, IL-6 levels increased significantly at the end of PP and $24 \mathrm{~h}$ after the surgery from baseline in the moderate NMB group, whereas there was no significant change in the deep NMB group. Meanwhile, CRP, which is one of acute phase response proteins of inflammation ${ }^{21}$, was comparable at $24 \mathrm{~h}$ after surgery in our study. TNFR- 1 mediates TNF-induced endothelial permeability, and its activation means compromised alveolar-capillary barrier and neutrophilic inflammation in the lungs ${ }^{22}$. In this study, TNFR-1 levels increased significantly from baseline after $\mathrm{PP}$ in both groups and was significantly higher in the moderate NMB group than in the deep NMB group at the end of PP and $24 \mathrm{~h}$ after the surgery, although there was no intergroup difference in the change in TNFR-1 level.

According to the detrimental impacts of PP on the blood circulation of intra-abdominal organs and cardiopulmonary functions ${ }^{23}$, low-pressure PP during laparoscopy has been tried with several benefits, but the evidence is weak yet ${ }^{8}$. In addition, low-pressure $\mathrm{PP}(<12 \mathrm{mmHg})$ in gynecological laparoscopy worsened the visualization of the surgical field on account of needing higher pressures than usual laparoscopy clinically ${ }^{24}$. However, these studies were not conducted at the identical depth of the $\mathrm{NMB}^{8,24}$. Whereas, Martini et al. firstly reported that deep NMB improved the quality of surgical conditions than moderate NMB during laparoscopy without cardiorespiratory compromise, which was conducted at the identical retroperitoneal pressure ${ }^{25}$. In a meta-analysis, deep NMB was found to improve the surgical space conditions at both low- and high-pressure $\mathrm{PP}^{7}$.

PP increases ventilation-perfusion mismatch and decreases lung compliance and tidal volume through cephalic elevation of the diaphragm ${ }^{6,26}$, which are accentuated by the steep Trendelenburg position ${ }^{27,28}$. During gynecologic laparoscopy, the establishment of IAP $12 \mathrm{mmHg}$ decreased the lung compliance up to $34 \%$ and 

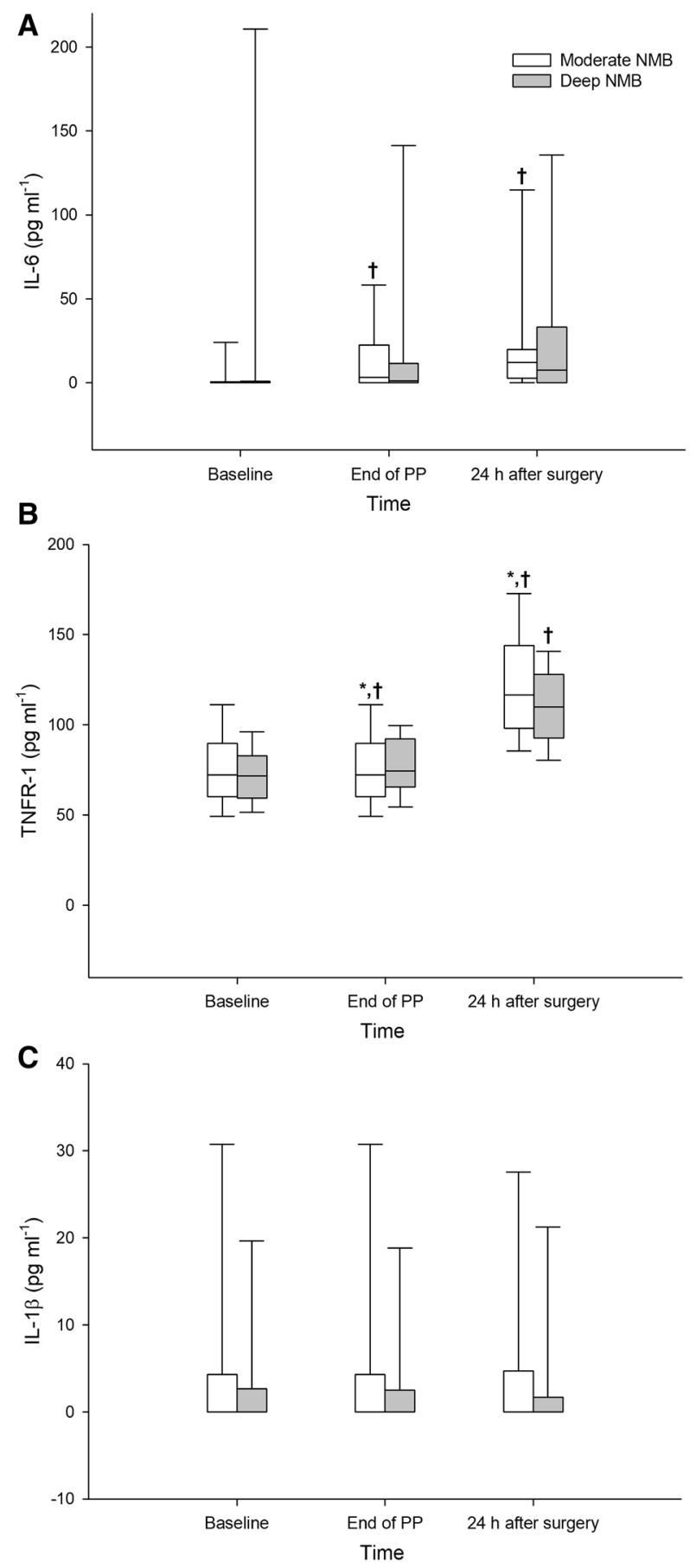

Figure 2. Changes in interleukin (IL)-6 (A), tumour necrosis factor receptor (TNFR)-1 (B), and IL-1 $\beta$ levels (C). Abbreviations: NMB neuromuscular block, $P P$ pneumoperitoneum, Baseline, after anesthetic induction. The box plots represent the median, interquartile range, and 10th and 90th percentile (whiskers). ${ }^{\star} P<0.05$ between-group comparison. ${ }^{\dagger} P<0.05$ versus baseline in each group.

increased Pplat and Ppeak by 6-7 $\mathrm{cmH}_{2} \mathrm{O}^{26}$, and change in IAP from 10 to $15 \mathrm{mmHg}$ led to $11 \%$ decrease in lung compliance and $12 \%$ increase in both Pplat and Ppeak ${ }^{28}$. Ppeak is elevated by a combination of reduced dynamic and static compliance. As opposed to Ppeak, Pplat is considered as the most important determinant of barotrauma, because it may most accurately reflect the end-inspiratory volume and thus, lung injury. In addition, Pdriving is considered as the key determinant of lung injury. In a meta-analysis including 3562 ARDS patients, Pdriving was the strongest independent variable associated with survival among ventilation variables ${ }^{29}$. In our study, deep NMB combined with low-pressure PP significantly lowered Ppeak, Pplat, and Pdriving, and thus it might suppress the inflammatory responses associated with ventilator-induced lung injury as compared with moderate NMB combined high-pressure PP. 


\begin{tabular}{|c|c|c|c|c|c|}
\hline & Baseline & 15 min after PP & 60 min after PP & End of surgery & $P_{\text {group }}{ }^{*}$ time value \\
\hline \multicolumn{5}{|c|}{ Peak inspiratory pressure $\left(\mathrm{cmH}_{2} \mathrm{O}\right)$} & 0.002 \\
\hline Moderate NMB & $16.7(2.2)$ & $26.9(4.0)^{*, \dagger}$ & $27.9(3.7)^{*, \dagger}$ & $19.7(2.9)^{*, \dagger}$ & \\
\hline Deep NMB & $15.5(2.7)$ & $23.7(4.0)^{\dagger}$ & $23.9(4.5)^{\dagger}$ & $18.2(3.0)^{\dagger}$ & \\
\hline \multicolumn{5}{|c|}{ Plateau airway pressure $\left(\mathrm{cmH}_{2} \mathrm{O}\right)$} & 0.003 \\
\hline Moderate NMB & $14.2(1.8)$ & $23.8(3.7)^{*, \dagger}$ & $24.4(3.1)^{*, \dagger}$ & $16.6(2.7)^{\dagger}$ & \\
\hline Deep NMB & $13.4(1.9)$ & $20.8(4.4)^{\dagger}$ & $21.0(4.2)^{\dagger}$ & $15.5(2.8)^{\dagger}$ & \\
\hline \multicolumn{5}{|c|}{ Driving airway pressure $\left(\mathrm{cmH}_{2} \mathrm{O}\right)$} & 0.003 \\
\hline Moderate NMB & $9.1(1.8)$ & $18.8(3.7)^{*, \dagger}$ & $19.4(3.1)^{*, \dagger}$ & $11.6(2.7)^{\dagger}$ & \\
\hline Deep NMB & $8.4(1.9)$ & $15.8(4.4)^{\dagger}$ & $16.0(4.2)^{\dagger}$ & $10.5(2.9)^{\dagger}$ & \\
\hline \multicolumn{5}{|c|}{ Mean airway pressure $\left(\mathrm{cmH}_{2} \mathrm{O}\right)$} & 0.048 \\
\hline Moderate NMB & $8.5(0.9)$ & $11.0(1.3)^{*, \dagger}$ & $11.2(1.3)^{*, \dagger}$ & $9.1(1.3)^{\dagger}$ & \\
\hline Deep NMB & $8.2(0.8)$ & $10.0(1.4)^{\dagger}$ & $10.2(1.5)^{\dagger}$ & $8.7(1.5)^{\dagger}$ & \\
\hline \multicolumn{5}{|c|}{ Static lung compliance $\left(\mathrm{mL} / \mathrm{cmH}_{2} \mathrm{O}\right)$} & 0.623 \\
\hline Moderate NMB & $41.0(7.5)$ & $20.3(4.0)^{*, \dagger}$ & $19.5(3.5)^{*, \dagger}$ & $33.4(7.5)^{\dagger}$ & \\
\hline Deep NMB & $43.8(7.5)$ & $25.2(9.1)^{\dagger}$ & $23.9(5.4)^{\dagger}$ & $36.0(7.2)^{\dagger}$ & \\
\hline \multicolumn{5}{|c|}{ Dynamic lung compliance $\left(\mathrm{mL} / \mathrm{cmH}_{2} \mathrm{O}\right)$} & 0.442 \\
\hline Moderate NMB & $32.2(7.7)$ & $17.4(3.6)^{*, \dagger}$ & $16.5(3.3)^{*, \dagger}$ & $26.3(6.4)^{\dagger}$ & \\
\hline Deep NMB & $36.2(10.0)$ & $20.4(4.1)^{\dagger}$ & $20.0(4.2)^{\dagger}$ & $28.7(6.6)^{\dagger}$ & \\
\hline
\end{tabular}

Table 2. Intraoperative respiratory mechanics. Values are presented as mean (standard deviation). Baseline means after anesthetic induction. Driving airway pressure means the pressure gradient from plateau pressure to positive end-expiratory pressure. Abbreviations: $N M B$ neuromuscular block. ${ }^{\star} P<0.05$ between-group comparison. ${ }^{\dagger} P<0.01$ versus 'baseline' in each group.

\begin{tabular}{|c|c|c|c|}
\hline & Moderate NMB $(n=33)$ & Deep NMB $(n=34)$ & $P$ value \\
\hline \multicolumn{4}{|l|}{ White blood cell count $(\mu / L)$} \\
\hline Preoperative & 6219 (1468) & 5585 (1575) & 0.115 \\
\hline $24 \mathrm{~h}$ after surgery & $8838(2585)$ & $8044(1832)$ & 0.215 \\
\hline C-reactive protein $(\mathrm{mg} / \mathrm{dL})$ & $1.1[0.2-5.6(0.6-2.2)]$ & $0.0[0.2-3.6(0.7-1.7)]$ & 0.649 \\
\hline Chest X-ray & $17 / 2 / 3$ & $17 / 2 / 3$ & $>0.999$ \\
\hline
\end{tabular}

Table 3. Postoperative data. Values are presented as mean (standard deviation), median [range (interquartile range)], and the number of patients. Abbreviations: NMB, neuromuscular block.

In a multicentre study (ACURASIS trial), early administration of an NMB agent, namely, cisatracurium, improved the outcome by decreasing biotrauma in $\mathrm{ARDS}^{13}$. It may be attributed to the anti-inflammatory properties of cisatracurium rather than to a consequence of the reduction in patient-ventilator asynchrony ${ }^{30}$. Although a new multicentre study (ROSE trial) detected no significant decrease on long-term mortality ${ }^{31}$, cisatracurium may reduce biotrauma and short-term mortality ${ }^{32}$. In our study, all patients were deep-sedated without asynchrony and received rocuronium as an aminosteroid $\mathrm{NMB}$ agent. In contrast to a report that rocuronium induced inflammation in vivo ${ }^{33}$, deep NMB plus low-pressure PP significantly reduced biotrauma in our study.

The current study has a few limitations. First, although the high IAP during mechanical ventilation increased inflammatory markers in the lungs ${ }^{14}$, the increase in systemic inflammatory cytokines might have resulted from other sites also. In rats, PP increased levels of IL-6 and TNF- $\alpha$ in the peritoneum or abdominal organs ${ }^{34,35}$. Second, all patients included in our study were female. Further validations are required in other gender populations. However, cytokines are related to the immune system; thus, changes in their concentrations induced by high pressure-PP or excessive $\mathrm{CO}_{2}$ absorption influence metabolism and phagocytotic ability of macrophages and decrease the cytotoxic activity of lymphocytes ${ }^{15}$. Therefore, our observation could be important, particularly in cancer patients, because immunosuppression is one of the factors responsible not only for postoperative infection but also for tumour spread and metastasis ${ }^{36}$.

In conclusion, the deep NMB combined with low-pressure PP significantly suppressed the increases in IL-6 level developed after PP, by significantly improving the respiratory mechanics compared to moderate NMB combined with high-pressure PP in a steep Trendelenburg position during robotic gynecologic surgery. 


\section{Methods}

After obtaining approval from the Ajou University Hospital Institutional Review Board (AJIRB-MEDOBS-18-115), this study was registered at http://clinicaltrials.gov (NCT 03576118). This study was performed in accordance with relevant guidelines and regulations. Between May 2018 and November 2019, 74 patients aged 25-80 years undergoing robotic gynecologic surgery with Trendelenburg position were enrolled. All participants provided written informed consent prior to randomization. The exclusion criteria were the presence of cerebrovascular disease, uncontrolled hypertension, asthma, neuromuscular disorder, a history of prior abdominal surgery, and morbid obesity (body mass index $>35 \mathrm{~kg} / \mathrm{m}^{2}$ ).

Interventions. Patients were randomly assigned to moderate or deep NMB groups using a computer-generated randomization technique (http://www.random.org). The moderate NMB group $(n=37)$ was maintained with a train of four (TOF) count of 1-2 and IAP at $12 \mathrm{mmHg}$ during surgery and then reversed using glycopyrrolate $(10 \mu \mathrm{g} / \mathrm{kg})$ and neostigmine $(50 \mu \mathrm{g} / \mathrm{kg})$ after surgery. The deep NMB group $(n=37)$ was maintained with a post-tetanic count of 1-2 and IAP at $8 \mathrm{mmHg}$ and then reversed using sugammadex (4 mg/kg). NMB was monitored using acceleromyography (TOF-Watch-SX; MSD BV, Netherlands), which was applied to the adductor pollicis muscle. The study intervention was conducted by an anesthetic provider who did not participate in the outcome assessment. Patients and outcome assessors of intraoperative and postoperative periods were blinded to the group assignment.

Anesthesia. Standard monitoring, including pulse oximetry, electrocardiography, bispectral index (BIS), and noninvasive blood pressure measurement, was performed. Anesthesia was implemented as total intravenous anesthesia using target-controlled infusion of propofol and remifentanil. Anesthesia was induced with propofol of $4.0-6.0 \mu \mathrm{g} / \mathrm{mL}$ and remifentanil of $3.0-4.0 \mu \mathrm{g} / \mathrm{mL}$ as target concentrations. After loss of consciousness, the TOF-Watch-SX was calibrated and stabilized ( $<5 \%$ variation in the TOF ratios). After administration of rocuronium $(0.6 \mathrm{mg} / \mathrm{kg})$ and subsequent confirmation of relaxation, tracheal intubation was performed. A 20-G radial arterial catheter was inserted for continuous monitoring of hemodynamics and blood sampling. Mechanical ventilation was composed of volume-controlled mode with a tidal volume $6 \mathrm{ml} / \mathrm{kg}$ of ideal body weight, an I:E ratio of 1:2, an external PEEP of $5 \mathrm{cmH}_{2} \mathrm{O}$, and an inspiratory pause of $10 \%\left(\mathrm{~F}_{\mathrm{I}} \mathrm{O}_{2}=0.5\right)$. Respiratory rate was set to an end-tidal carbon dioxide tension $\left(\mathrm{EtCO}_{2}\right)$ between 30 and $40 \mathrm{mmHg}$. Ideal body weight was calculated according to a predefined formula for women: $45.5+0.919 \times[\text { height }(\mathrm{cm})-152.4]^{37}$. Anesthesia was maintained using propofol and remifentanil to achieve the BIS value of 40-60 and mean arterial pressure (MAP) within $20 \%$ of baseline. Rocuronium $(0.3-0.4 \mathrm{mg} / \mathrm{kg} / \mathrm{h})$ was continuously infused and titrated according to the group assignment until the end of the fascia suturing. After dressing, the NMB was reversed, and extubation was done after confirming the TOF ratio $>0.9$. Lactate Ringer's solution or normal saline was infused at a rate of $6 \mathrm{ml} / \mathrm{kg} / \mathrm{h}$.

Trendelenburg position was set at $30^{\circ}$. PP was controlled by limiting $\mathrm{CO}_{2}$ insufflator. For patient-controlled analgesia, intravenous fentanyl was administered for $48 \mathrm{~h}$ at a rate of $0.4 \mu \mathrm{g} / \mathrm{kg} / \mathrm{h}$ depending on the patient's need.

Data collection. Pro-inflammatory cytokine levels, including interleukin (IL)-6, tumour necrosis factor (TNF)- $\alpha$, TNF receptor (TNFR)-1, and IL-1 $\beta$, and anti-inflammatory cytokines, including IL-4 and IL-10, were measured. Blood samples were collected at 3 time points: after induction (baseline), at the end of PP, and $24 \mathrm{~h}$ after surgery; they were transferred to EDTA tubes and sent to the laboratory in a container. They were centrifuged at $3600 \mathrm{rpm}$ for $30 \mathrm{~min}$ and $1.5 \mathrm{~mL}$ of the supernatant serum was collected in an Eppendorf tube which was subsequently frozen at $-80^{\circ} \mathrm{C}$ for later analysis. The levels of cytokines were measured using a commercially available ELISA kit (R\&D Systems, Minneapolis, Minnesota, USA). Each sample was analyzed in triplicates and excluded when at least one was not determined, and the average value was calculated.

Respiratory parameters, including peak inspiratory pressure (Ppeak), plateau airway pressure (Pplat), mean airway pressure (Pmean), and $\mathrm{EtCO}_{2}$, were recorded at 4 time points: after induction (baseline), 15 min and 60 min after PP, and at the end of surgery. Driving airway pressure (Pdriving) means pressure gradient from the plateau pressure to PEEP. The heart rate (HR), MAP, and parameters associated with arterial blood gas analysis $\left(\mathrm{pH}, \mathrm{PaO}_{2}\right.$, and $\mathrm{PaCO}_{2}$ ) were recorded at 5 time points: after induction (baseline), 15 min and 60 min after PP, at the end of PP, and at the end of surgery. The arterial blood samples were analyzed using a satellite blood-gas analyzer (Stat Profile pHOx Ultra, Nova Biomedical, Waltham, MA, USA). White blood cell count was measured preoperatively and $24 \mathrm{~h}$ after surgery. C-reactive protein (CRP, normal range $\leq 0.5 \mathrm{mg} / \mathrm{dL}$ ) and chest X-ray were evaluated at $24 \mathrm{~h}$ after surgery.

Statistical analysis. The primary endpoint was the change in the level of IL- 6 during the surgery. The secondary endpoints were the changes in levels of other pro-inflammatory cytokines, anti-inflammatory cytokines, and respiratory parameters during the surgery. A previous study reported that the mean \pm standard deviation (SD) value of IL-6 level was $45 \pm 8.6 \mathrm{pg} / \mathrm{L}$ during mechanical ventilation after conventional $\mathrm{PP}^{38}$. Based on this previous result, we assumed that a $15 \%$ reduction in IL-6 level might be clinically significant. With an $\alpha$-error of 0.05 and a $\beta$-error of $90 \%, 36$ subjects were required in each group. We included 37 patients per group to allow for possible dropouts.

Values are expressed as mean (SD or standard error) or median [range (interquartile range)] or numbers of patients. The normality of distribution was assessed with the Kolmogorov-Smirnov test. Parametric data and nonparametric data were analyzed using the independent $t$ test and the Mann-Whitney $U$ test, respectively. Categorical variables were evaluated using the chi-square test or Fisher's exact test. Intergroup comparisons for repeated-measures, including $\mathrm{HR}, \mathrm{MAP}, \mathrm{pH}, \mathrm{PaO}_{2}, \mathrm{PaCO}_{2}$, respiratory parameters, and cytokines were performed using a linear mixed model with post hoc analyses as fixed effects. A $P$ value $<0.05$ was considered statistically 
significant. Statistical analysis was conducted using SAS (version 9.3, SAS Inc., Cary, NC, USA) and R package (version 3. 6.1).

Received: 3 September 2020; Accepted: 8 January 2021

Published online: 21 January 2021

\section{References}

1. Xu, Q. et al. Postoperative comparison of laparoscopic radical resection and open abdominal radical hysterectomy for cervical cancer patient. Arch. Gynecol. Obstet. 302, 473-479 (2020).

2. Jeong, J. S. et al. Comparison of perioperative outcomes between pure laparoscopic surgery and open right hepatectomy in living donor hepatectomy: Propensity score matching analysis. Sci. Rep. 10, 5314 (2020).

3. Yan, Q., Xu, L.-B., Ren, Z.-F. \& Liu, C. Robotic versus open pancreaticoduodenectomy: A meta-analysis of short-term outcomes. Surg. Endosc. 34, 501-509 (2020).

4. Sammour, T. et al. Systematic review of oxidative stress associated with pneumoperitoneum. Br. J. Surg. 96, 836-850 (2009).

5. Ypsilantis, P. et al. Room air versus carbon dioxide pneumoperitoneum: Effects on oxidative state, apoptosis and histology of splanchnic organs. Surg. Endosc. 30, 1388-1395 (2016).

6. Neudecker, J. et al. The European Association for Endoscopic Surgery clinical practice guideline on the pneumoperitoneum for laparoscopic surgery. Surg. Endosc. 16, 1121-1143 (2002).

7. Bruintjes, M. H. et al. Deep neuromuscular block to optimize surgical space conditions during laparoscopic surgery: A systematic review and meta-analysis. Br. J. Anaesth. 118, 834-842 (2017).

8. Ozdemir-van Brunschot, D. M. et al. What is the evidence for the use of low-pressure pneumoperitoneum? A systematic review. Surg. Endosc. 30, 2049-2065 (2016).

9. Curley, G. F., Laffey, J. G., Zhang, H. \& Slutsky, A. S. Biotrauma and ventilator-induced lung injury: Clinical implications. Chest 150, 1109-1117 (2016)

10. Kim, H. J. et al. Effect of combining a recruitment maneuver with protective ventilation on inflammatory responses in video-assisted thoracoscopic lobectomy: A randomized controlled trial. Surg. Endosc. 33, 1403-1411 (2019).

11. Park, S. J. et al. Effects of intraoperative protective lung ventilation on postoperative pulmonary complications in patients with laparoscopic surgery: Prospective, randomized and controlled trial. Surg. Endosc. 30, 4598-4606 (2016).

12. Kokulu, S. et al. Impact of a lung-protective ventilatory strategy on systemic and pulmonary inflammatory responses during laparoscopic surgery: Is it really helpful?. Inflammation 38, 361-367 (2015).

13. Papazian, L. et al. Neuromuscular blockers in early acute respiratory distress syndrome. N. Engl. J. Med. 363, 1107-1116 (2010).

14. Brandao, J., Dato, C., Gaspar, V. \& Oliveira Junior, I. Effects of intra-abdominal pressure in rat lung tissues after pneumoperitoneum. Int. J. Clin. Exp. Med. 12, 8309-8317 (2019)

15. Buunen, M. et al. Stress response to laparoscopic surgery: A review. Surg. Endosc. 18, 1022-1028 (2004).

16. Schietroma, M. et al. A prospective randomized study of systemic inflammation and immune response after laparoscopic Nissen fundoplication performed with standard and low-pressure pneumoperitoneum. Surg. Laparosc. Endosc. Percutan. Tech. 23, 189-196 (2013).

17. Basgul, E. et al. Effects of low and high intra-abdominal pressure on immune response in laparoscopic cholecystectomy. Saudi Med. J. 25, 1888-1891 (2004).

18. Perrakis, E. et al. Randomized comparison between different insufflation pressures for laparoscopic cholecystectomy. Surg. Laparosc. Endosc. Percutan. Technol. 13, 245-249 (2003).

19. Torres, K. et al. A comparative study of angiogenic and cytokine responses after laparoscopic cholecystectomy performed with standard- and low-pressure pneumoperitoneum. Surg. Endosc. 23, 2117-2123 (2009).

20. Vijayaraghavan, N. et al. Comparison of standard-pressure and low-pressure pneumoperitoneum in laparoscopic cholecystectomy: A double blinded randomized controlled study. Surg. Laparosc. Endosc. Percutan. Tech. 24, 127-133 (2014).

21. Alazawi, W., Pirmadjid, N., Lahiri, R. \& Bhattacharya, S. Inflammatory and immune responses to surgery and their clinical impact. Ann. Surg. 264, 73-80 (2016).

22. Proudfoot, A. et al. Novel anti-tumour necrosis factor receptor-1 (TNFR1) domain antibody prevents pulmonary inflammation in experimental acute lung injury. Thorax 73, 723-730 (2018).

23. de Lacy, F. B. et al. Impact of pneumoperitoneum on intra-abdominal microcirculation blood flow: An experimental randomized controlled study of two insufflator models during transanal total mesorectal excision: An experimental randomized multi-arm trial with parallel treatment design. Surg. Endosc. https://doi.org/10.1007/s00464-00019-07236-00465 (2019).

24. Kyle, E. B., Maheux-Lacroix, S., Boutin, A., Laberge, P. Y. \& Lemyre, M. Low vs standard pressures in gynecologic laparoscopy: A systematic review. JSLS 20, 201500113 (2016).

25. Martini, C. H., Boon, M., Bevers, R. F., Aarts, L. P. \& Dahan, A. Evaluation of surgical conditions during laparoscopic surgery in patients with moderate vs deep neuromuscular block. Br. J. Anaesth. 112, 498-505 (2014).

26. Suh, M. K., Seong, K. W., Jung, S. H. \& Kim, S. S. The effect of pneumoperitoneum and Trendelenburg position on respiratory mechanics during pelviscopic surgery. Korean J. Anesthesiol. 59, 329-334 (2010).

27. Rubini, A., Monte, D. D. \& Catena, V. Effects of the pneumoperitoneum and Trendelenburg position on respiratory mechanics in the rats by the end-inflation occlusion method. Ann. Thorac. Med. 7, 205-209 (2012).

28. Park, J. S. et al. Effects of pneumoperitoneal pressure and position changes on respiratory mechanics during laparoscopic colectomy. Korean J. Anesthesiol. 63, 419-424 (2012).

29. Amato, M. B. et al. Driving pressure and survival in the acute respiratory distress syndrome. N. Engl. J. Med. 372, 747-755 (2015).

30. Forel, J. M. et al. Neuromuscular blocking agents decrease inflammatory response in patients presenting with acute respiratory distress syndrome. Crit. Care Med. 34, 2749-2757 (2006).

31. Park, S. \& Schmidt, M. Early neuromuscular blockade in moderate to severe acute respiratory distress syndrome: Do not throw the baby out with the bathwater!. J. Thorac. Dis. 11, E231-e234 (2019).

32. Zheng, Z. et al. Neuromuscular blocking agents for acute respiratory distress syndrome: An updated meta-analysis of randomized controlled trials. Respir. Res. 21, 23-23 (2020).

33. Baek, S. B. et al. Rocuronium bromide inhibits inflammation and pain by suppressing nitric oxide production and enhancing prostaglandin E2 synthesis in endothelial cells. Int. Neurourol. J. 20, 296-303 (2016).

34. Papparella, A. et al. Peritoneal morphological changes due to pneumoperitoneum: The effect of intra-abdominal pressure. Eur. J. Pediatr. Surg. 24, 322-327 (2014).

35. Ates, E., Yilmaz, S., Ihtiyar, E., Yasar, B. \& Karahuseyinoglu, E. Preconditioning-like amelioration of erythropoietin against laparoscopy-induced oxidative injury. Surg. Endosc. 20, 815-819 (2006).

36. Rossaint, J. \& Zarbock, A. Perioperative inflammation and its modulation by anesthetics. Anesth. Analg. 126, 1058-1067 (2018).

37. Brower, R. G. et al. Ventilation with lower tidal volumes as compared with traditional tidal volumes for acute lung injury and the acute respiratory distress syndrome. N. Engl. J. Med. 342, 1301-1308 (2000). 
38. Han, C., Ding, Z., Fan, J., Sun, J. \& Qian, Y. Comparison of the stress response in patients undergoing gynecological laparoscopic surgery using carbon dioxide pneumoperitoneum or abdominal wall-lifting methods. J. Laparoendosc. Adv. Surg. Technol. A 22, $330-335(2012)$

\section{Author contributions}

Conception and design: J.Y.K. and H.J.K.; Provision of study materials or patients: S.K.M.; Collection and assembly of data: E.H. and J.Y.K.; Data analysis and interpretation: J.E.K. and D.L.; Manuscript writing: J.E.K., J.Y.K. and H.J.K.; Final approval of manuscript: All authors.

\section{Funding}

This work was supported in part by a research grant from the Investigator-Initiated Studies Program of Merck Sharp \& Dohme Corp.

\section{Competing interests}

The authors declare no competing interests.

\section{Additional information}

Correspondence and requests for materials should be addressed to J.Y.K. or H.J.K.

Reprints and permissions information is available at www.nature.com/reprints.

Publisher's note Springer Nature remains neutral with regard to jurisdictional claims in published maps and institutional affiliations.

(c) (i) Open Access This article is licensed under a Creative Commons Attribution 4.0 International License, which permits use, sharing, adaptation, distribution and reproduction in any medium or format, as long as you give appropriate credit to the original author(s) and the source, provide a link to the Creative Commons licence, and indicate if changes were made. The images or other third party material in this article are included in the article's Creative Commons licence, unless indicated otherwise in a credit line to the material. If material is not included in the article's Creative Commons licence and your intended use is not permitted by statutory regulation or exceeds the permitted use, you will need to obtain permission directly from the copyright holder. To view a copy of this licence, visit http://creativecommons.org/licenses/by/4.0/.

(C) The Author(s) 2021 